\title{
Peripartal feeding strategy with different $n-6: n-3$ ratios in sows: effects on sows' performance, inflammatory and periparturient metabolic parameters
}

\author{
Georgios A. Papadopoulos ${ }^{1,2}$, Dominiek G. D. Maes $^{2}$, Stephanie Van Weyenberg ${ }^{1}$, Theo A. T. G. van
} Kempen $^{3}$, Johan Buyse ${ }^{4}$ and Geert P. J. Janssens ${ }^{1}$

${ }^{1}$ Laboratory of Animal Nutrition, Faculty of Veterinary Medicine, Ghent University, Heidestraat 19, B-9820 Merelbeke, Belgium

${ }^{2}$ Department of Reproduction, Obstetrics and Herd Health, Faculty of Veterinary Medicine, Ghent University, Salisburylaan 133, B-9820, Merelbeke, Belgium

${ }^{3}$ Provimi Research and Innovation Centre, Lenneke Marelaan 2, B-1932 Sint-Stevens-Woluwe, Belgium

${ }^{4}$ Laboratory of Physiology, Immunology and Genetics of Domestic Animals, Department of Biosystems, Catholic University of Leuven, Kasteelpark Arenberg 30, B-3001 Heverlee, Belgium

(Received 17 January 2008 - Revised 15 May 2008 - Accepted 21 May 2008 - First published online 10 July 2008)

The present study aimed to investigate the effects of two lactation sow feeds, differing in $n-6: n-3$ ratio, given to sows before parturition on body condition and feed intake, periparturient metabolism (leptin, insulin, triiodothyronine $\left(\mathrm{T}_{3}\right)$ and thyroxine $\left(\mathrm{T}_{4}\right)$ ), inflammatory parameters (TNF $\alpha$, IL-6, serum amyloid A (SAA)) and on piglet performance (birth weight, survivability). The feed contained either a low (supplemented with fish oil; f groups) or high (supplemented with sunflower-seed oil; s groups) $n-6: n-3$ ratio and was administered from $8 \mathrm{~d}$ (f8, s8) or $3 \mathrm{~d}$ (f3, s3) before parturition until weaning. The level of inclusion of the oil sources was $2 \%$. Seventy-two sows were randomly allocated $8 \mathrm{~d}$ before expected farrowing into four groups: $\mathrm{f} 3, \mathrm{f} 8, \mathrm{~s} 3$, s8. Type of feed had a significant influence on the sows' feed intake during the first $2 \mathrm{~d}$ of lactation $\left(\mathrm{s}<\mathrm{f}\right.$ ), leptin on days 4,3 and 2 before parturition $\left(\mathrm{f}<\mathrm{s}\right.$ ), insulin on day 1 after parturition ( $\mathrm{f}<\mathrm{s}$ ), $\mathrm{T}_{4}$ on the day before parturition $(\mathrm{s}<\mathrm{f})$ and rectal temperature on the day after parturition $(\mathrm{f}<\mathrm{s})$. Onset of administration of the feed $(3 v .8 \mathrm{~d})$ had significant effects on leptin on day 2 before parturition $(8<3)$, insulin on day 4 before parturition $(3<8), \mathrm{T}_{3}$ on day 4 before parturition and on the day after parturition $(3<8)$, SAA on day 3 after parturition $(8<3)$ and piglet weight during the first days postpartum $(3<8)$. In conclusion, under the present conditions, a lactation feed low in $n-6: n-3$ ratio administered from $8 \mathrm{~d}$ before farrowing ensures improved feed intake during the first days postpartum and was associated with a better metabolic change and inflammatory profile in sows in the periparturient period.

Lactating sows: $n-6: n-3$ ratio: Fatty acids: Leptin: Insulin

Commercial pig diets are based on cereals and protein feed which hardly contain long-chain $n-3$ fatty acids ${ }^{(1)}$. Actual requirements of the $n-6$ and $n-3$ families of fatty acids in pig diets and the ideal ratio of $n-6: n-3^{(2)}$ are still a matter of research. The $n-6$ and $n-3$ PUFA have distinct properties. It has been suggested that a high intake of $n-6$ PUFA, especially arachidonic acid, can contribute to inflammatory processes and predispose to or exacerbate inflammatory diseases ${ }^{(3,4)}$. Moreover, $n-6$ and $n-3$ PUFA are involved in glucose and lipid metabolism. A high $n-6: n-3$ ratio is considered to be a critical factor in both insulin resistance and atherosclerosis in studies in man and animal models ${ }^{(5)}$.

A moderate replacement of safflower-seed oil with tuna oil prevented the development of insulin resistance at the wholebody level in Wistar rats ${ }^{(6)}$. Moreover, in rats the addition of long-chain $n-3$ PUFA to the diet resulted in the amelioration of insulin resistance ${ }^{(7)}$. Postpartum hypophagia in sows was shown to be related to decreased glucose tolerance and increased insulin resistance ${ }^{(8)}$. Therefore, it could be hypothesised that in the case of providing a diet for sows with a low $n-6: n-3$ ratio, insulin action and consequently postpartum feed intake would be improved, whereas diets with a high $n-6: n-3$ ratio would not exert these benefits.

During the past years, the effects of inclusion of $n-3$ and $n-6$ PUFA in sow diets on performance parameters and on accretion by the piglets have been studied. Piglet growth was improved when supplementing tuna oil at a level of $1.75 \%$ at different periods during gestation ${ }^{(1)}$. Supplementation of salmon oil to the sow diets during gestation and lactation at a level of $1.65 \%$ reduced pre-weaning mortality ${ }^{(9)}$. It was shown that the proportions of $n-3$ and $n-6$ PUFA in piglet brain and liver at birth depend on the fatty acid composition

Abbreviations: f, low n-3: $n-6$ ratio feed supplemented with fish oil; f3, group with feed $\mathrm{f}$ administered $3 \mathrm{~d}$ before parturition until weaning; f8, group with feed $\mathrm{f}$ administered $8 \mathrm{~d}$ before parturition until weaning; s, high n-3:n-6 ratio feed supplemented with sunflower-seed oil; s3, group with feed s administered $3 \mathrm{~d}$ before parturition until weaning; $\mathrm{s} 8$, group with feed s administered $8 \mathrm{~d}$ before parturition until weaning; $\mathrm{SAA}$, serum amyloid A; $\mathrm{T}_{3}$, triiodothyronine; $\mathrm{T}_{4}$, thyroxine. * Corresponding author: Dr G. A. Papadopoulos, fax +3292647848, email georgios.papadopoulos@ugent.be 
of the maternal diet, when oil sources were supplemented at a level of $1.75 \%$ during pregnancy ${ }^{(10)}$. The low $n-6: n-3$ ratio used in these and in other studies ${ }^{(11)}$ ranged between 0.9 and $4 \cdot 3$, while the high ratio ranged from $6 \cdot 6$ to $15 \cdot 3$. For the present study an inclusion level of $2 \%$ was decided, thus obtaining a low $(2 \cdot 1)$ and a high $(10 \cdot 1) n-6: n-3$ ratio.

The periparturient period in sows ranges from $4 \mathrm{~d}$ before to $3 \mathrm{~d}$ after parturition ${ }^{(12)}$. Feeding sows ad libitum a lactation diet either from $4 \mathrm{~d}$ before the expected day of farrowing or from the farrowing day onwards, instead of the introduction of ad libitum feeding from $3 \mathrm{~d}$ after farrowing, resulted in higher daily feed intake and less mobilisation of body reserves by the sows ${ }^{(13)}$. Furthermore, elevated rectal temperatures and increased incidence of agalactia (now described as postpartum dysgalactia syndrome $\left.{ }^{(14)}\right)$ were reported in sows given feed ad libitum from farrowing compared with sows given the gestation feeding level until $3 \mathrm{~d}$ after farrowing ${ }^{(15)}$. Moreover, when sows were fed restrictively during the last 2 weeks of gestation, a higher feeding level was associated with elevated rectal temperatures and an increased incidence of agalactia ${ }^{(16)}$. The transition from a gestation to a lactation diet in sows commonly takes place when sows are transferred from gestation rooms to the farrowing crates. Depending on the study, the transition may occur at day $107^{(17,18)}, 108^{(19)}$, $109^{(20)}, 110^{(21)}$ or $111^{(22)}$ of gestation.

It has not yet been investigated in sows, fed restrictively, whether the time point of the transition from a gestation to a lactation diet during late gestation (earlier: $8 \mathrm{~d}$ or closer: $3 \mathrm{~d}$ to parturition), in combination with lactation diets differing in the $n-6: n-3$ ratio, would have an effect on parameters in sows related to performance, metabolism and inflammatory processes. Based on the properties of $n-6$ and $n$-3 PUFA, it could be hypothesised that a lactation diet with a high $n-6: n-3$ ratio would increase inflammatory parameters, compared with a lactation diet with a low $n-6: n-3$ ratio. Leptin would be an interesting parameter for investigation, since it could be indicative of energy balance in pigs ${ }^{(23)}$. It has been shown in gilts that acute changes in feed intake can affect leptin secretion $^{(24)}$. In addition, it is interesting to investigate the association between maternal levels of leptin and insulin during the periparturient period with progeny performance, as poor glucose tolerance of sows during late gestation was reported to be a risk factor for the survival of pigs after birth ${ }^{(25)}$.

The present trial was set up to elucidate the consequences of the $n-6: n-3$ ratio of a lactation diet, a low $v$. a high ratio, in combination with the time point of transition from a gestation to a lactation diet in sows, either at 8 or $3 \mathrm{~d}$ before farrowing. Piglet viability and growth during lactation, sows' body condition and feed intake during lactation, parameters related to metabolism during the periparturient period and inflammatory parameters postpartum were monitored. Finally, associations between levels of leptin and insulin in sows during the periparturient period and progeny performance were also investigated.

\section{Materials and methods}

\section{Study population and experimental design}

The study was conducted in the Provimi Research Farm, Velddriel, The Netherlands at the end of 2006 and the beginning of 2007. In total, seventy-two pregnant hybrid sows (Topigs 20 breed; Dutch Landrace $\times$ Great York) were included. The experimental period started at day 107 of gestation and ended when the piglets were weaned at day 21 of lactation. The experimental protocol of the study was approved by the ethical committee of the Animal Sciences Group in Wageningen, The Netherlands.

Until day 107 of gestation, the sows were group-housed in a gestation unit and they were fed twice per $\mathrm{d}$ with a conventional gestation diet $(4 \mathrm{~kg} / \mathrm{d})$. The composition $(\mathrm{g} / \mathrm{kg})$ of this feed was: DM, 892; ash, 67; crude protein, 126; crude fat, 34; neutral-detergent fibre, 197; metabolisable energy, $10400 \mathrm{~kJ} / \mathrm{kg}$. Linoleic content was $11.53 \mathrm{~g} / \mathrm{kg}$, total $n-3$ PUFA was $1.66 \mathrm{~g} / \mathrm{kg}$, and DHA and EPA content was fairly low, i.e. $4.09 \times 10^{-5} \mathrm{~g} / \mathrm{kg}$ and $3.47 \times 10^{-5} \mathrm{~g} / \mathrm{kg}$, respectively.

At day 107 of gestation, the pregnant sows were moved to the farrowing rooms, and they were randomly allocated using a $2 \times 2$ experimental design to four different treatment groups, namely $\mathrm{f} 3, \mathrm{f} 8, \mathrm{~s} 3$, s8. Sows from the $\mathrm{f}$ and the $\mathrm{s}$ groups received a lactation diet that was supplemented with a fish oil product, or a sunflower-seed oil product, respectively. The final level of inclusion of fish oil was $2 \%$, while in the other group the level of inclusion of sunflower-seed oil was $1.5 \%$ and soyabean oil was included at $0.5 \%$ in order to achieve the final $n-6: n-3$ ratio. The $n-6: n-3$ ratios in these feeds were 2.09 and 10.13 for the $f$ and s groups, respectively (Table 1). Half of the sows belonging either to the $f$ group or the $\mathrm{s}$ group received the experimental lactation diets from day 107 of gestation (f8 and s8 groups) onwards ( $8 \mathrm{~d}$ before expected farrowing); the other half of the sows received the experimental lactation feed only from day 111 of gestation ( $\mathrm{f} 3$ and $\mathrm{s} 3$ group) onwards, being $3 \mathrm{~d}$ before the expected day of farrowing (onset day groups). The latter sows continued to receive the conventional gestation feed between day 107 and day 111 of gestation. The allowance of feed before and after farrowing was according to the common practice in the herd. From day 107 of gestation onwards, the sows from all four groups received the same amount of feed, namely $3.3 \mathrm{~kg} / \mathrm{sow}$ per d. An overview of energy and major nutrient supply in the four experimental groups before farrowing is given in Table 2 . The herd practised a 3-week batch production system, and the seventy-two sows farrowed in three consecutive batches of twenty-four sows each. Within each batch, the sows were randomly assigned to the four experimental groups. The mean parity of sows per experimental group (f3 $=4 \cdot 2 ; \quad \mathrm{f} 8=4.4$; s3 $=4.6$; s8 $=4.3)$ was not significantly different between the groups $(P=0.570)$.

No feed was provided on the day of parturition (D0). From the first day of lactation onwards until weaning, the sows were fed twice per d, namely at 08.00 hours and again at 18.00 hours. The amount of feed that was provided daily was $3.0 \mathrm{~kg}$ on D1 and D2, $3.5 \mathrm{~kg}$ on D3, $4.0 \mathrm{~kg}$ on D4 and D5, $4.5 \mathrm{~kg}$ on D6 and D7, $5.0 \mathrm{~kg}$ on D8 and D9, and $5.5 \mathrm{~kg}$ from D10 until D21. The amount of feed consumed by every sow was recorded daily from D1 until D21. The feeding troughs were emptied and checked each evening.

Sows were weighed on a digital scale when they were placed in the farrowing crates (day 107 of gestation; D-8) and at weaning (D21). On these occasions, also backfat measurements using a digital backfat indicator (Renco Lean 
Table 1. Chemical composition of the two different feeds for the sows*

\begin{tabular}{lrc}
\hline & \multicolumn{2}{c}{ Diet supplement } \\
\cline { 2 - 3 } & Fish oil & Sunflower-seed oil \\
\hline Diet $(\mathrm{g} / \mathrm{kg})$ & 899 & \\
DM & 65 & 886 \\
Ash & 171 & 65 \\
Crude protein & 61 & 167 \\
Crude fat & 181 & 61 \\
Neutral-detergent fibre & 12300 & 181 \\
Metabolisable energy (kJ/kg) & & \\
Fatty acids (\% total fatty acids) & $33 \cdot 5$ & $26 \cdot 5$ \\
SFA & $33 \cdot 4$ & $29 \cdot 7$ \\
MUFA & $33 \cdot 1$ & $43 \cdot 3$ \\
PUFA & & \\
Total $n-6$ (\% PUFA) & $20 \cdot 9$ & $38 \cdot 3$ \\
$18: 2 n-6$ & $0 \cdot 2$ & $0 \cdot 2$ \\
$20: 4 n-6$ & & \\
Total $n-3$ (\% PUFA) & $2 \cdot 1$ & $2 \cdot 4$ \\
$18: 3 n-3$ & $1 \cdot 4$ & $0 \cdot 3$ \\
$18: 4 n-3$ & $0 \cdot 2$ & $\mathrm{ND}$ \\
$20: 4 n-3$ & $2 \cdot 8$ & $0 \cdot 4$ \\
$20: 5 n-3$ & $0 \cdot 2$ & $0 \cdot 1$ \\
$22: 5 n-3$ & $3 \cdot 4$ & $0 \cdot 6$ \\
$22: 6 n-3$ & $2 \cdot 09$ & $10 \cdot 13$ \\
$n-6: n-3$ &
\end{tabular}

$\mathrm{ND}$, not detected.

*The feeds were supplemented either with fish oil or with sunflower-seed oil and differed in the $n-6: n-3$ ratio.

Meter) were made of every sow. Backfat levels were measured at three positions on each side of the sows: position A (position A left and position A right), between the crossing backside of the shoulder and the spine, $5 \mathrm{~cm}$ to the left and

Table 2. Overview of the energy and major nutrient supply (per d) in sows in every experimental group before farrowing*

\begin{tabular}{ccc}
\hline & $\begin{array}{c}\text { Between days } 107 \text { and } 111 \\
\text { of gestation }\end{array}$ & $\begin{array}{c}\text { Between day 111 of gestation } \\
\text { and farrowing }\end{array}$ \\
\hline $\begin{array}{l}\text { Metabolisable energy (kJ/d) } \\
\text { f3 } \\
\text { f8 }\end{array}$ & \\
s3 & 40600 & 40600 \\
s8 & 34300 & 40600 \\
Protein (g/d) & 40600 & 40600 \\
f3 & & 40600 \\
f8 & $415 \cdot 8$ & \\
s3 & $564 \cdot 3$ & $564 \cdot 3$ \\
s8 & $415 \cdot 8$ & $564 \cdot 3$ \\
Fat (g/d) & $551 \cdot 1$ & $551 \cdot 1$ \\
f3 & $112 \cdot 2$ & $551 \cdot 1$ \\
f8 & $201 \cdot 3$ & $201 \cdot 3$ \\
s3 & $112 \cdot 2$ & $201 \cdot 3$ \\
s8 & $201 \cdot 3$ & $201 \cdot 3$ \\
Neutral-detergent fibre $(\mathrm{g} / \mathrm{d})$ & $201 \cdot 3$ \\
f3 & $605 \cdot 1$ & \\
f8 & $597 \cdot 3$ & $597 \cdot 3$ \\
s3 & $605 \cdot 1$ & $597 \cdot 3$ \\
s8 & $597 \cdot 3$ & $597 \cdot 3$ \\
\end{tabular}

f, Low $n-3: n-6$ ratio feed supplemented with fish oil; $f 3$, group with feed $f$ administered $3 \mathrm{~d}$ before parturition until weaning; $\mathrm{f} 8$, group with feed $f$ administered $8 \mathrm{~d}$ before parturition until weaning; $s$, high $n-3: n-6$ ratio feed supplemented with sunflower-seed oil; $s 3$, group with feed $s$ administered $3 \mathrm{~d}$ before parturition until weaning; $\mathrm{s} 8$, group with feed $\mathrm{s}$ administered $8 \mathrm{~d}$ before parturition until weaning.

* The feed contained either a low (supplemented with fish oil; f groups) or high (supplemented with sunflower-seed oil; s groups) $n-6: n-3$ ratio and was provided from 8 or $3 d$ before parturition (onset day 8 or 3 ).
$5 \mathrm{~cm}$ to the right; position $\mathrm{C}$ (position $\mathrm{C}$ left and position $\mathrm{C}$ right), in the crossing between the last rib and the spine, $5 \mathrm{~cm}$ left of the spine and $5 \mathrm{~cm}$ right of the spine; position $\mathrm{B}$ (position $\mathrm{B}$ left and position $\mathrm{B}$ right), $5 \mathrm{~cm}$ left and $5 \mathrm{~cm}$ right of the spine in between points $\mathrm{A}$ and $\mathrm{C}$.

Blood samples were taken from every sow daily from D-4 (day 110 of gestation) until parturition (D0). Two additional blood samples were taken after farrowing, namely at D1 and D3. The samples were taken before the morning meal by puncture of the jugular vein in vacuum tubes. The parameters analysed in serum were leptin, glucose, insulin, triiodothyronine $\left(\mathrm{T}_{3}\right)$, thyroxine $\left(\mathrm{T}_{4}\right)$, VLDL, while $\mathrm{TNF} \alpha$, IL-6 and serum amyloid A (SAA) were analysed in plasma. An overview of the examined parameters in blood is given in Table 3. The rectal temperature of the sows was recorded with a digital thermometer (accuracy $0 \cdot 1^{\circ} \mathrm{C}$ ) at the first day of lactation, before morning feeding and before blood sampling.

Piglets were individually identified and weighed within $1-2 \mathrm{~h}$ after completion of birth, or during the next morning when sows farrowed during the night. The piglets were individually weighed at D1, D2, D7, D14 and D21. The accuracy of the digital scale was $0.005 \mathrm{~kg}$. The number of stillborn, the number of piglets that died until weaning and the number of piglets weaned was recorded. Cross-fostering of piglets was allowed only during D1 and only in between sows of the same experimental group. There was not an effort to equalise the litters.

\section{Analytical procedures}

Insulin was analysed by BioSource INS-IRMA KIP1251 and KIP1254 methods (BioSource Europe S.A., Nivelles, Belgium). Thyroid hormones $\left(\mathrm{T}_{3}\right.$ and $\mathrm{T}_{4}$ ) were analysed by using a specific RIA. Leptin was determined using a commercially available RIA test kit (Multi-Species Leptin RIA Kit, catalogue number XL-85K; Linco Research, Inc., St Charles, MO, USA). Glucose was analysed by an enzymic method (Gluco-quant) on a Roche/Hitachi Modular. TAG were analysed with TAG GPO-PAP (Roche/Hitachi, Vilvoorde, Belgium) Reagent 1, 11876023 216. VLDL was determined by the Friedewald equation (TAG/5). TNF $\alpha$ was analysed by a porcine TNF $\alpha$ immunoassay (Quantikine; R\&D Systems, Minneapolis, MN, USA). IL-6 was analysed by a porcine IL-6 quantitative sandwich enzyme immunoassay technique

Table 3. Overview of the different parameters that were analysed in blood from the seventy-two sows included in the study*

\begin{tabular}{|c|c|c|c|c|c|c|c|}
\hline Parameters & D-4 & D-3 & $\mathrm{D}-2$ & $D-1$ & Do & D1 & D3 \\
\hline Insulin & $x$ & & & $x$ & & $x$ & $\times$ \\
\hline $\mathrm{T}_{3}, \mathrm{~T}_{4}$ & $\times$ & & & $x$ & & $x$ & $\times$ \\
\hline Glucose & $\times$ & & & $x$ & & $\times$ & $x$ \\
\hline Leptin & $x$ & $x$ & $x$ & $x$ & & $x$ & $\times$ \\
\hline VLDL & $x$ & & & $x$ & & $x$ & $\times$ \\
\hline TAG & $x$ & & & $x$ & & $x$ & $\times$ \\
\hline TNF $\alpha$, IL-6, SAA & & & & & & $x$ & $\times$ \\
\hline
\end{tabular}

$\times$, Parameter was analysed; $T_{3}$, triiodothyronine; $T_{4}$, thyroxine; SAA, serum amyloid $A$.

*Blood samples were taken daily from $4 \mathrm{~d}$ before parturition (D-4) until parturition (D0), and on D1 and D3 after parturition. 
(Quantikine; R\&D Systems). SAA was analysed by a solidphase sandwich ELISA kit (Tridelta Phase ${ }^{\mathrm{TM}}$; Tridelta PLC, Bray, Co. Wicklow, Republic of Ireland). All samples were analysed in duplicate and in the same array, in order to avoid inter-array variation.

\section{Statistical analyses}

All examined parameters in blood, feed intake of the sows, litter weight and litter growth, piglet weight and piglet growth, backfat and weight of the sows were analysed with two-way ANOVA at each time point separately using SPSS 15.0 (SPSS, Inc., Chicago, IL, USA). This type of analysis was selected to enable a clear view at which time point significant differences of the examined parameters between the experimental groups occurred. Specifically, individual piglet weights were pooled per litter, and afterwards the mean individual piglet weight and mean individual piglet growth were used for the statistical procedures. Survival analysis, including the effect of mortality level in the different groups and the time of death, was used to analyse the difference in survivability of the piglets. The type of feed (fish oil $v$. sunflower-seed oil-supplemented) and the duration of providing the experimental feed (onset day $3 v$. diet day 8 ) were included as fixed factors in the models. Correlations between the examined parameters were investigated using Pearson's correlations. Mean values with their standard errors were calculated for each experimental group separately (f3, f8, s3, s8). The level of significance was at $P \leq 0.05$ (two-sided test).

\section{Results}

Piglets

Survivability of piglets between the four treatment groups is shown in Fig. 1.

Mean individual piglet weights, piglet growth, litter weights and litter growth in the four treatment groups are presented in Table 4. Piglet weight on D0, D1 and D2 was higher for the onset 8 groups than onset 3 groups $(P=0.008, P=0.004$, $P=0.002$ at D0, D1 and D2, respectively). Piglet growth between D0 and D2 was higher in the onset 8 groups than in the onset 3 groups $(P=0 \cdot 048)$.

\section{Sow body condition and feed intake}

The mean backfat levels at day 108 of gestation and at weaning were not statistically significant for all positions measured. At position $\mathrm{A}, \mathrm{f} 3=28.3 \mathrm{~mm}$; $\mathrm{f} 8=28.5 \mathrm{~mm}$; $33=28.5 \mathrm{~mm}$; $\mathrm{s} 8=28.5 \mathrm{~mm}(P=0.921)$; at position $\mathrm{B}, \mathrm{f} 3=21.7 \mathrm{~mm}$; $\mathrm{f} 8=$ $22 \mathrm{~mm} ; \mathrm{s} 3=22 \mathrm{~mm}$; $\mathrm{s} 8=22 \mathrm{~mm}(P=0.853)$; at position $\mathrm{C}$, $\mathrm{f} 3=20.7 \mathrm{~mm} ; \mathrm{f} 8=20.8 \mathrm{~mm} ; \mathrm{s} 3=20.7 \mathrm{~mm} ; \mathrm{s} 8=20.9 \mathrm{~mm}$ $(P=0.908)$. The differences in backfat levels between day 108 of gestation and weaning are indicated in Fig. 2.

The sows belonging in the $\mathrm{s}$ group consumed less feed than the sows belonging in the $f$ group during the first $2 \mathrm{~d}$ of lactation (for D1, $P=0.003$; for D2, $P=0.014$ ) (Fig. 3).

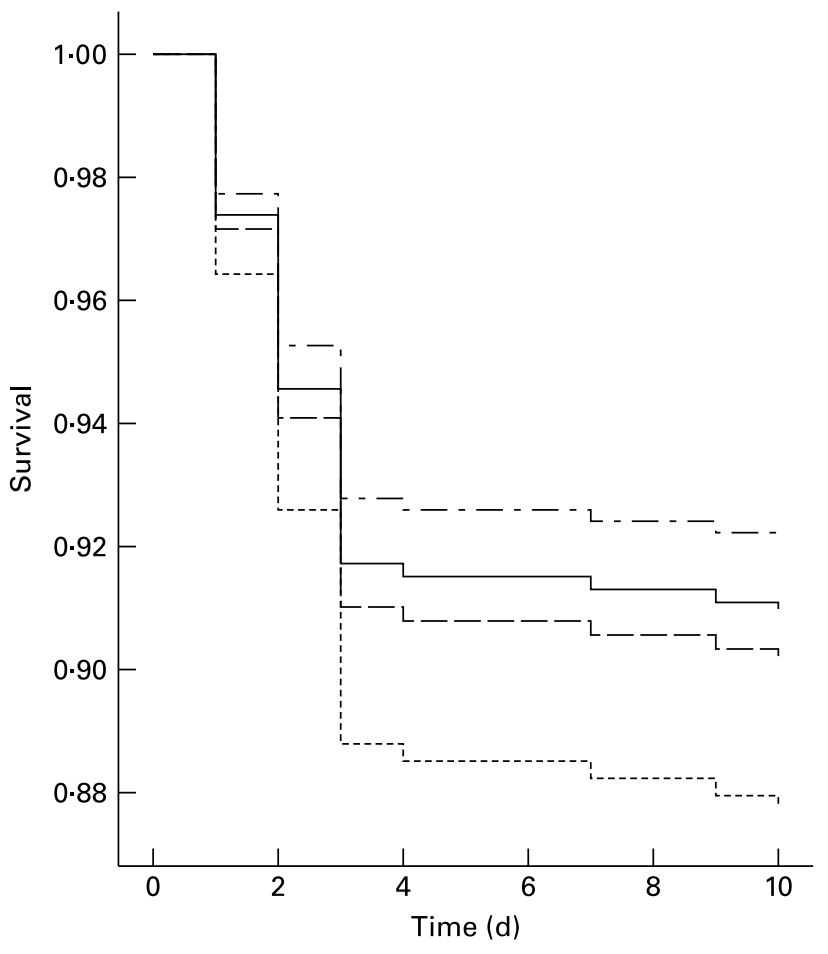

Fig. 1. Survival curves for piglet survivability during lactation from the four experimental diet groups in which sows were assigned. The feed contained either a low (supplemented with fish oil; $f$ groups) or high (supplemented with sunflower-seed oil; s groups) $n-6: n-3$ ratio and was provided from $8 \mathrm{~d}$ (f8 (---)), s8 (- - -)) or 3d (f3 (-), s3 (-- )) before parturition. Differences in survivability were not significant $(P>0.05)$. No losses of piglets occurred after day 10 of lactation and until weaning (day 21).

\section{Sow metabolism and immunology parameters}

The results of the parameters related to sow metabolism and immunology are presented in Table 5 and Figs. 4 and 5. On $\mathrm{D}-4$, sows in the onset 8 groups had higher insulin levels than those in the onset 3 groups $(P=0.021)$. On D1, sows in the $s$ group had higher insulin levels than the $f$ group $(P=0.029)$ (Fig. 4). Insulin on D-1 was overall negatively correlated with litter weight (Table 6).

$\mathrm{T}_{3}$ on D-4 was higher in the onset 8 than in the onset 3 group $(P<0.001)$. On D-1, the interaction between diet type and onset day was significant for $\mathrm{T}_{3}$ levels: in the $f$ group $\mathrm{T}_{3}$ was higher in $\mathrm{f} 3$ than $\mathrm{f8}$, but in the $\mathrm{s}$ group $\mathrm{T}_{3}$ was higher in s8 than $\mathrm{s} 3(P=0 \cdot 001)$. On $\mathrm{D} 1, \mathrm{~T}_{3}$ was higher in the onset 8 than the onset 3 groups $(P=0.001)$. On D-4, $\mathrm{T}_{4}$ concentrations were higher in the onset 3 than the onset 8 groups $(P=0.046)$. On $\mathrm{D}-1, \mathrm{~T}_{4}$ levels were higher in the $\mathrm{f}$ than the $\mathrm{s}$ group $(P=0 \cdot 048)$.

Leptin levels on D-4, D-3 and D-2 were higher in the s than the $\mathrm{f}$ groups $(P=0.047, P=0.005, P=0.031$, respectively) (Fig. 4). Leptin on D-2 was higher in the onset 3 than in the onset 8 groups $(P=0.003)$ (Fig. 4). When leptin data were pooled across all treatment groups, significant negative correlations were found between leptin on D-4 and leptin on D-3 with litter weight and litter growth in different stages (Tables 6 and 7) . Furthermore, significant positive correlations existed between pooled leptin and insulin postpartum values on $\mathrm{D} 1(r 0.432 ; P=0.001)$ and $\mathrm{D} 3(r 0.453 ; P=0.002)$. 
Table 4. Performance data (piglet and litter weight, piglet and litter growth) during lactation of the piglets from the sows of the four experimental groups†

(Mean values with standard errors from pooled data)

\begin{tabular}{|c|c|c|c|c|c|c|}
\hline & \multicolumn{4}{|c|}{ Experimental group } & \multirow[b]{2}{*}{ SE } & \multirow[b]{2}{*}{ Significance } \\
\hline & f3 & f8 & s3 & s8 & & \\
\hline Day 0 & $1 \cdot 30$ & 1.41 & $1 \cdot 28$ & 1.43 & 0.024 & ${ }^{* *} \mathrm{O}$ \\
\hline Day 1 & 1.40 & 1.53 & 1.38 & 1.55 & 0.026 & ${ }^{* \star} \mathrm{O}$ \\
\hline Day 2 & 1.57 & $1 \cdot 71$ & 1.53 & 1.74 & 0.029 & **o \\
\hline Day 7 & $2 \cdot 43$ & 2.58 & $2 \cdot 45$ & 2.52 & 0.052 & NS \\
\hline Day 21 & $6 \cdot 19$ & 6.53 & $6 \cdot 22$ & 6.54 & 0.099 & NS \\
\hline \multicolumn{7}{|c|}{ Piglet growth (g/d) } \\
\hline Days $0-1$ & 96 & 109 & 91 & 110 & 4.5 & NS \\
\hline Days $1-2$ & 144 & 174 & 144 & 159 & $6 \cdot 7$ & NS \\
\hline Days $0-2$ & 121 & 142 & 119 & 137 & 4.9 & ${ }^{*} \mathrm{O}$ \\
\hline Days $0-7$ & 158 & 162 & 168 & 150 & $6 \cdot 3$ & NS \\
\hline Days $7-14$ & 274 & 282 & 278 & 292 & 4.9 & NS \\
\hline Days $14-21$ & 256 & 280 & 264 & 282 & $5 \cdot 4$ & NS \\
\hline \multicolumn{7}{|l|}{ Litter weight (kg) } \\
\hline Day 0 & 14 & 16 & 16 & 16 & 0.4 & NS \\
\hline Day 1 & 15 & 17 & 17 & 17 & 0.5 & NS \\
\hline Day 2 & 17 & 19 & 18 & 18 & 0.5 & NS \\
\hline Day 7 & 26 & 29 & 29 & 26 & 0.9 & NS \\
\hline Day 14 & 47 & 50 & 51 & 48 & $1 \cdot 6$ & NS \\
\hline Day 21 & 65 & 71 & 73 & 68 & $2 \cdot 1$ & NS \\
\hline \multicolumn{7}{|c|}{ Litter growth $(\mathrm{g} / \mathrm{d})$} \\
\hline Days $0-1$ & 807 & 1000 & 764 & 977 & $79 \cdot 1$ & NS \\
\hline Days 1-2 & 1327 & 1861 & 1303 & 1230 & $108 \cdot 2$ & NS \\
\hline Days $0-2$ & 1067 & 1430 & 1033 & 1104 & 78.2 & NS \\
\hline Days $0-7$ & 1620 & 1800 & 1821 & 1478 & $88 \cdot 2$ & NS \\
\hline Days $7-14$ & 2946 & 3047 & 3233 & 3036 & $98 \cdot 1$ & NS \\
\hline Days 14-21 & 2731 & 3072 & 3131 & 2954 & $100 \cdot 1$ & NS \\
\hline Days $0-21$ & 2432 & 2639 & 2729 & 2490 & $86 \cdot 0$ & NS \\
\hline
\end{tabular}

$\mathrm{f}$, Low $n-3: n-6$ ratio feed supplemented with fish oil; $\mathrm{f} 3$, group with feed $\mathrm{f}$ administered $3 \mathrm{~d}$ before parturition until weaning; f8, group with feed $\mathrm{f}$ administered $8 \mathrm{~d}$ before parturition until weaning; $s$, high $n-3: n-6$ ratio feed supplemented with sunflower-seed oil; s3, group with feed $s$ administered $3 \mathrm{~d}$ before parturition until weaning; s8, group with feed $\mathrm{s}$ administered $8 \mathrm{~d}$ before parturition until weaning; $\mathrm{o}$, onset day effect.

${ }^{\star} P<0.05,{ }^{* *} P<0.01$.

†The feed contained either a low (supplemented with fish oil; $f$ groups) or high (supplemented with sunflower-seed oil; s groups) $n$-6: $n-3$ ratio and was provided from 8 or $3 \mathrm{~d}$ before parturition (onset day 8 or 3 )

On D-4, onset 3 groups had higher VLDL and TAG concentrations than the onset 8 groups $(P<0.001$ for both parameters). On D-1, s groups had higher VLDL and TAG concentrations than the froups $(P=0 \cdot 015)$.

TNF $\alpha$, IL-6 and SAA concentrations between the experimental groups on D1 and D3 are shown in Fig. 5. SAA on D3 was higher for the onset 3 group than the onset 8 group $(P=0.039)$. Rectal temperature on D1 was higher in the $\mathrm{s}$ than the $\mathrm{f}$ group $(P=0.041)$ (Fig. 5).

\section{Discussion}

The earlier transition from the gestation to a lactation diet $(8$ v. $3 \mathrm{~d}$ ) led to an increase in neonatal piglet weight and subsequent growth. Although the increase in fetal weight during late gestation in sows reaches a plateau ${ }^{(26)}$, it appears that the time point of diet change during the last days of gestation can affect piglet weight. This effect might be due to an increased transfer of energy and nutrients to the piglets in utero. The lactation diets used in the present study were superior in these elements comparing with the gestation diet.
In the present study, differences in feed consumption in sows during the first days of lactation were significant, even though sows of all groups were fed restrictively on an ascending scale and not on an ad libitum basis after farrowing. Feed consumption was lower when sows were fed the high $n-6: n-3$ ratio lactation diet. This may be attributed to the higher leptin levels during the periparturient period detected in this particular group in comparison with the other group. It has been described previously that intracerebroventricular treatment with leptin decreased feed intake in a dose-dependent manner in prepuberal gilts ${ }^{(27)}$. The role of insulin in this phenomenon should not be excluded. Central insulin action is catabolic (reducing feed intake and body weight), whereas its peripheral action is anabolic ${ }^{(28)}$. The high $n-6: n-3$ ratio diet induced higher insulin levels in sows at D1. Therefore, a peripheral insulin resistance may have occurred, while the central action of insulin may have remained unaltered.

After farrowing, an increase in insulin was triggered in all treatment groups. Increased insulin levels after parturition may play a role in partitioning nutrients to the mammary tissue $^{(29)}$ at the onset of milk production. Yet, as mentioned, insulin was higher at D1 when sows consumed the high 


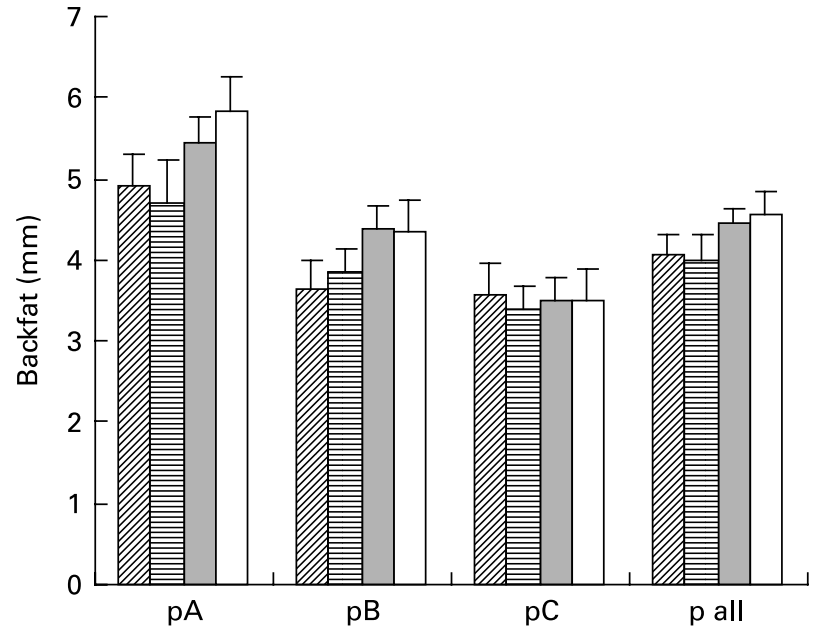

Fig. 2. Losses in backfat levels measured at day 108 of gestation and at

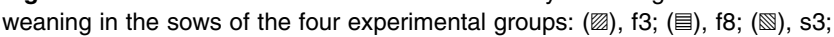
$(\square)$, s8. The feed contained either a low (supplemented with fish oil; f groups) or high (supplemented with sunflower-seed oil; s groups) $n-6: n-3$ ratio and was provided from $8 \mathrm{~d}(\mathrm{f} 8, \mathrm{~s} 8)$ or $3 \mathrm{~d}(\mathrm{f} 3, \mathrm{~s} 3)$ before parturition. Backfat was measured at three different positions: position $A(p A)$ between the crossing backside shoulder and spine; position $B(p B)$ at an equal distance between $\mathrm{pA}$ and position $\mathrm{C}(\mathrm{pC}) ; \mathrm{pC}$ in the crossing between the last rib and spine. $\mathrm{p}$ all, Average of backfat levels at the three positions. Values are means, with standard errors represented by vertical bars. No significant differences were found between the four experimental groups on the same position $(P>0.05)$.

$n-6: n-3$ ratio diet. Results from male miniature pigs suggest that substitution of $n$-3 for $n$-6 PUFA in dietary lipids is associated with enhanced insulin sensitivity ${ }^{(30)}$. In addition, fasting hyperinsulinaemia is present early in the process of diabetes and is thought to be a compensatory mechanism to maintain euglycaemia in the setting of insulin resistance ${ }^{(31)}$. Moreover, comparatively high levels of insulin in sows during lactation correspond to lower catabolic status and lower milk production ${ }^{(32)}$. It is therefore possible that in

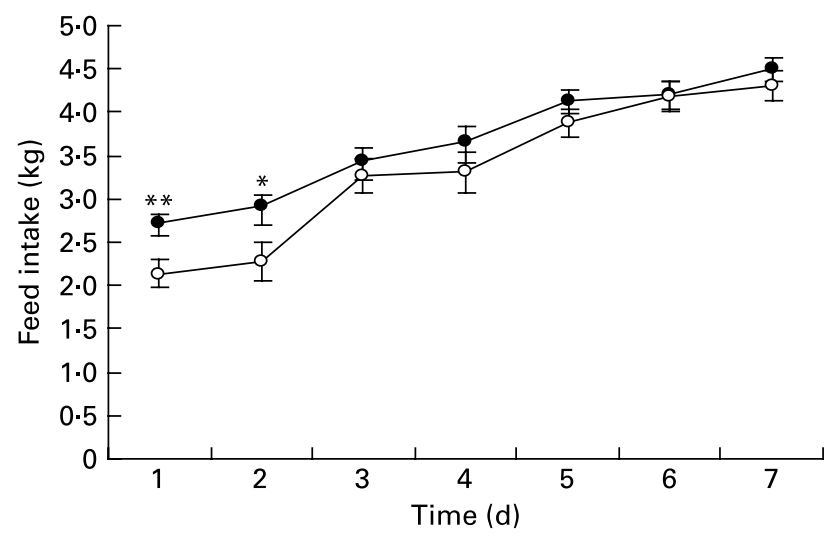

Fig. 3. Feed intake of sows during the first $7 d$ of lactation in the two diettype groups. Sows were receiving two types of lactation diets differing in the $n-6: n-3$ ratio (the low ratio diet supplemented with fish oil; the high ratio diet supplemented with sunflower-seed oil), administered from two time points onwards before parturition. (○), Sunflower-seed oil-supplemented group; $(\bullet)$, fish oil-supplemented group. Values are means for each experimental group, with their standard errors represented by vertical bars. Mean value was significantly different from that of the sunflower-seed oil-supplemented group: ${ }^{\star} P<0.05,{ }^{*} P<0.01$. comparison with the low $n-6: n-3$ ratio groups, a short period of peripheral insulin resistance might have been developed after parturition in the high $n-6: n-3$ ratio groups.

$\mathrm{T}_{3}$ was increased and $\mathrm{T}_{4}$ was decreased at D-4 in the groups that already have shifted to the lactation diets (onset 8 group). This indicated a higher conversion of $\mathrm{T}_{4}$ into $\mathrm{T}_{3}$. Again at D1, $\mathrm{T}_{3}$ was higher in that experimental group. The secretions of the thyroid gland are involved with many metabolic functions including stimulating $\mathrm{O}_{2}$ consumption and protein synthesis by the mammary gland and concomitantly increasing milk yield ${ }^{(33)}$. Impaired thyroid action had been speculated to be linked with the occurrence of the postpartum dysgalactia syndrome. Normal postpartum sows had significantly higher thyroid cell heights than either the agalactic or cyclic sows ${ }^{(34)}$.

Leptin levels were affected by acute feeding events before farrowing, such as the transition from the gestation to the lactation diets. Between D-4 and D0, the time profile of leptin in sows receiving the lactation diets from $3 \mathrm{~d}$ pre-partum showed an increase and a subsequent spontaneous decrease. During the same period, the sows receiving the lactation diets from $8 \mathrm{~d}$ pre-partum already had the highest concentration of leptin. Of course, due to the absence of samples before D-4, such a profile in the sows in the $8 \mathrm{~d}$ group can only be hypothesised.

In the present study pre-farrowing levels of insulin and leptin in sows appeared to be associated with piglet performance. Similar findings were observed in rats ${ }^{(35)}$, in which exogenous leptin given centrally in rats was associated with reduced litter weight gain. In addition, poor glucose tolerance of pregnant sows was reported previously ${ }^{(25)}$ to be a risk factor for survival of pigs after birth. The precise mechanism underlying this relationship remains to be elucidated. In pigs, placental glucose transport occurs by a carrier-mediated facilitated diffusion involving several glucose transport isoforms, mainly GLUT1 ${ }^{(36,37)}$. Most probably, pre-farrowing maternal levels of leptin and insulin affect these energy-dependent mechanisms and consequently affect litter weight at birth.

VLDL and TAG concentrations at D-4 were lower in the groups receiving already the lactation diets. This may indicate an increased rate of $\beta$-oxidation in the liver ${ }^{(37)}$. VLDL and TAG concentrations were increased at $1 \mathrm{~d}$ pre-partum by a high dietary $n-6: n-3$ ratio lactation diet. This suggests increased hepatic lipogenesis in these sows. Increased lipogenesis might not be related to changes in thyroid hormones, but might be more related to the lipogenic activity of the increased insulin.

The sows belonging to the high $n-6: n-3$ ratio group had significantly higher rectal temperatures. This can be attributed to the well-described pro-inflammatory properties of the $n-6$ fatty acids ${ }^{(3,4)}$. At D3, SAA levels were significantly higher in the onset 3 groups. Thus, SAA levels in sows postpartum can be affected by factors other than pathogenic challenges, as previously reported ${ }^{(38)}$.

In conclusion, a lactation diet high in $n-6: n-3$ ratio was associated with higher leptin levels pre- and postpartum, a short-term peripheral insulin resistance on the first day of lactation and a decreased feed intake of sows on the first and second day of lactation. An increase in leptin concentration in the sows receiving the gestation diet until day 111 of gestation occurred after the acute elevation of the energy level, by offering these sows the lactation diet. Besides the effects 
Table 5. Mean values of glucose, triiodothyronine $\left(T_{3}\right)$, thyroxine $\left(T_{4}\right)$, VLDL and TAG in the sows of the four experimental groups around parturition (D0) $\dagger$ (Mean values with standard errors from pooled data)

\begin{tabular}{|c|c|c|c|c|c|c|}
\hline \multirow[b]{2}{*}{ Time of measurement } & \multicolumn{4}{|c|}{ Experimental group } & \multirow[b]{2}{*}{ SE } & \multirow[b]{2}{*}{ Significance } \\
\hline & f3 & f8 & s3 & s8 & & \\
\hline \multicolumn{7}{|l|}{ Glucose $(\mathrm{mmol} / \mathrm{l})$} \\
\hline D-4 & 3.882 & 4.003 & 3.975 & 3.715 & 0.052 & NS \\
\hline D-1 & 3.996 & 3.802 & 3.975 & 3.940 & 0.045 & NS \\
\hline D1 & 3.750 & 4.380 & $4 \cdot 240$ & 4.127 & 0.116 & NS \\
\hline D3 & $4 \cdot 130$ & 3.908 & 3.957 & 3.958 & 0.101 & NS \\
\hline \multicolumn{7}{|l|}{$\mathrm{T}_{3}(\mathrm{ng} / \mathrm{ml})$} \\
\hline D-4 & 0.155 & 0.237 & 0.140 & 0.215 & 0.008 & $* * O_{0}$ \\
\hline D-1 & 0.186 & 0.150 & 0.117 & 0.176 & 0.007 & $\star \star \star \star$ to \\
\hline D1 & 0.252 & 0.414 & 0.281 & 0.340 & 0.017 & ${ }^{* \star *} \mathrm{O}$ \\
\hline D3 & 0.306 & 0.343 & 0.285 & 0.317 & 0.012 & NS \\
\hline \multicolumn{7}{|l|}{$\mathrm{T}_{4}(\mathrm{ng} / \mathrm{ml})$} \\
\hline D-4 & $16 \cdot 066$ & 13.020 & 14.516 & $12 \cdot 768$ & 0.596 & *o \\
\hline D-1 & $10 \cdot 856$ & 10.999 & $7 \cdot 859$ & 10.449 & 0.455 & ${ }^{*} \mathrm{t}$ \\
\hline D1 & $18 \cdot 167$ & 20.574 & $18 \cdot 278$ & 19.932 & 0.749 & NS \\
\hline D3 & 14.470 & $15 \cdot 224$ & 13.002 & $15 \cdot 548$ & 0.551 & NS \\
\hline \multicolumn{7}{|l|}{ VLDL (mg/l) } \\
\hline $\mathrm{D}-4$ & $166 \cdot 83$ & $125 \cdot 17$ & 214.36 & 124.00 & 9.19 & $\star \star \star 0$ \\
\hline D-1 & 61.00 & 61.33 & 96.80 & $69 \cdot 20$ & 4.71 & ${ }^{*} \mathrm{t}$ \\
\hline D1 & $72 \cdot 70$ & $66 \cdot 00$ & 89.90 & $70 \cdot 70$ & 4.31 & NS \\
\hline D3 & 58.62 & 55.47 & 48.88 & $55 \cdot 20$ & $2 \cdot 70$ & NS \\
\hline \multicolumn{7}{|l|}{ TAG (mg/l) } \\
\hline D-4 & $834 \cdot 20$ & $625 \cdot 80$ & 1071.80 & 620.00 & 45.97 & ${ }^{\star \star \star} \mathrm{O}$ \\
\hline D-1 & $305 \cdot 00$ & $306 \cdot 70$ & 484.00 & 346.00 & 23.57 & ${ }^{*} \mathrm{t}$ \\
\hline D1 & 363.60 & 330.00 & $449 \cdot 30$ & 353.30 & 21.57 & NS \\
\hline D3 & $293 \cdot 10$ & 277.30 & $275 \cdot 90$ & 276.00 & $15 \cdot 75$ & NS \\
\hline
\end{tabular}

$\mathrm{f}$, Low $n-3: n-6$ ratio feed supplemented with fish oil; $\mathrm{f} 3$, group with feed $\mathrm{f}$ administered $3 \mathrm{~d}$ before parturition until weaning; f8, group with feed $\mathrm{f}$ administered $8 \mathrm{~d}$ before parturition until weaning; s, high $n-3: n-6$ ratio feed supplemented with sunflower-seed oil; s3, group with feed $\mathrm{s}$ administered $3 \mathrm{~d}$ before parturition until weaning; s8, group with feed $s$ administered $8 \mathrm{~d}$ before parturition until weaning; o, onset day effect; $t$, diet type effect; to, interaction between diet type and onset day. ${ }^{\star} P<0.05,{ }^{\star \star} P<0.01,{ }^{\star \star \star} P<0.001$

†The feed contained either a low (supplemented with fish oil; f groups) or high (supplemented with sunflower-seed oil; s groups) $n-6: n-3$ ratio and was provided from 8 or $3 \mathrm{~d}$ before parturition (onset day 8 or 3 ).
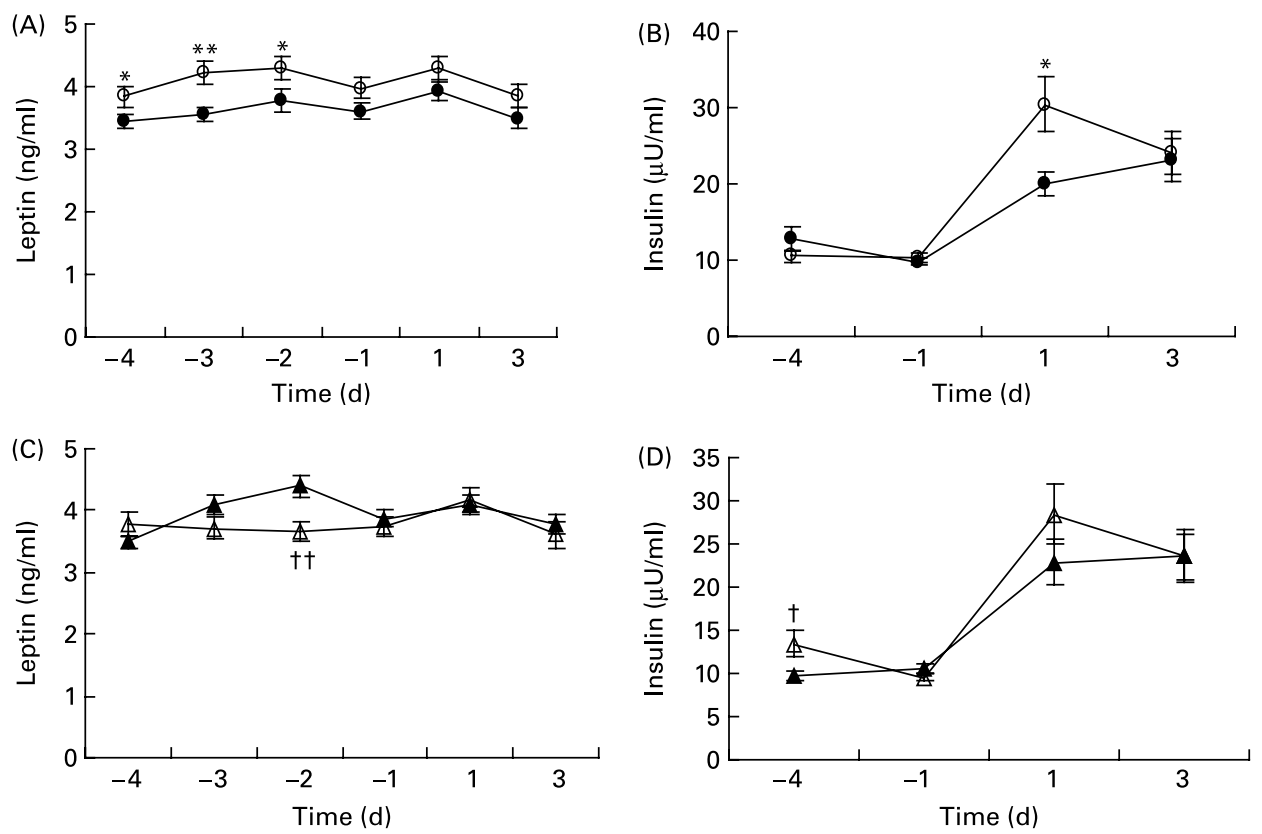

Fig. 4. Leptin (A, C) and insulin (B, D) in sows $(n 71)$ during the periparturient period of $-4 \mathrm{~d}$ before farrowing to $3 \mathrm{~d}$ after farrowing. Sows received two lactation diets differing in the $n-6: n-3$ ratio (the low ratio diet supplemented with fish oil $(\bullet)$; the high ratio diet supplemented with sunflower-seed oil $(O)$ ), administered from two time points onwards before parturition ( $8 \mathrm{~d}(\Delta)$ or $3 \mathrm{~d}(\mathbf{\Lambda})$ before farrowing; onset 8 or 3 groups). (A) Leptin in the two diet-type groups. (B) Insulin in the two diet-type groups. (C) Leptin in the two diet-day groups. (D) Insulin in the two diet-day groups. Values are means, with standard errors represented by vertical bars. Mean value was significantly different from that of the fish oil-supplemented group: ${ }^{*} P<0.05,{ }^{\star \star} P<0.01$. Mean value was significantly different from that of the onset 3 group: $\dagger P<0.005$, $\dagger+P<0.01$. 


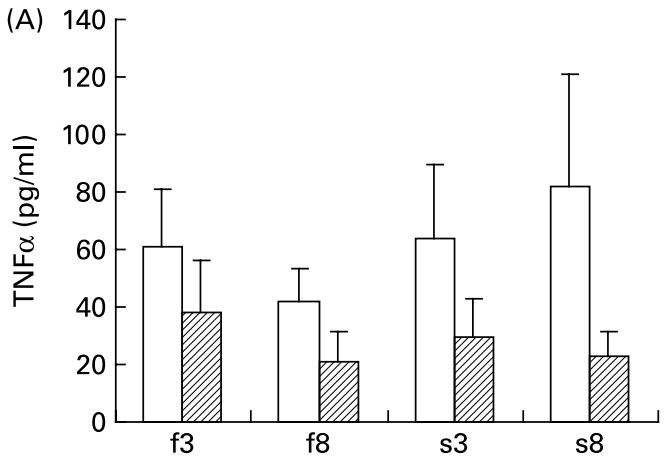

(B)
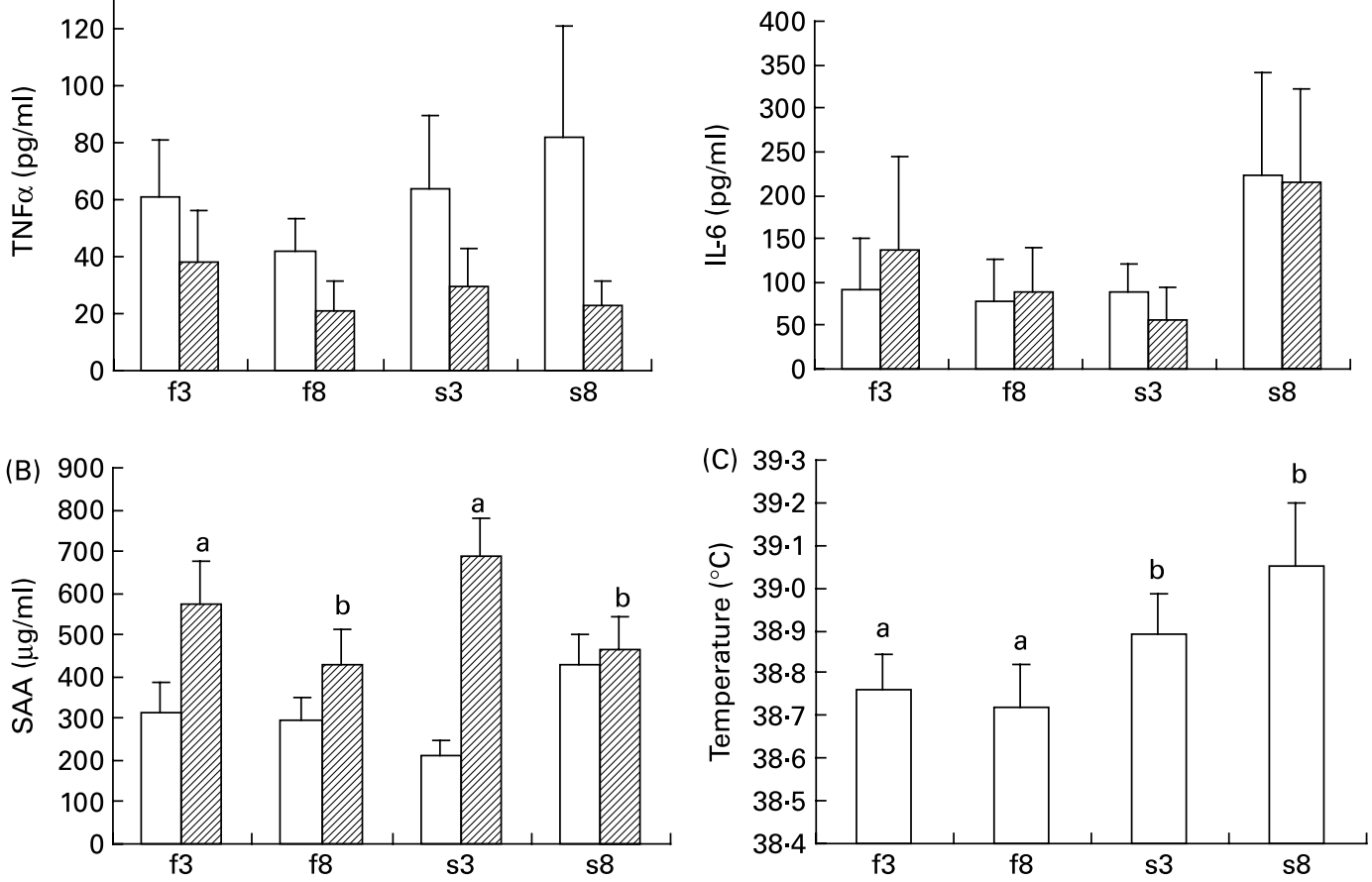

Fig. 5. TNF $\alpha(A)$, IL-6 (B), serum amyloid A (SAA; (C)) and rectal temperature (D) of the sows $(n 71)$ at the first $(\square)$ and third day ( $\mathbb{Q}$ ) of lactation. Sows were receiving two types of lactation diets differing in the $n-6: n-3$ ratio (the low ratio diet supplemented with fish oil; the high ratio diet supplemented with sunflowerseed oil), administered from two time points onwards before parturition ( $8 \mathrm{~d}$ or $3 \mathrm{~d}$ before farrowing; onset 3 or 8 groups). f3, Fish oil-onset 3 ; f8, fish oil-onset 8 ; s3, sunflower-seed oil-onset 3 ; s8, sunflower-seed oil-onset 8 . Values are means, with standard errors represented by vertical bars. ${ }^{a, b}$ Mean values within the same day of measurement with unlike letters were significantly different $(P<0.05)$.

Table 6. Associations (Pearson's correlation; $r$ ) between sow insulin levels $1 \mathrm{~d}$ before farrowing (D-1) and leptin levels on the fourth and third day before farrowing (D-4 and D-3 respectively) from the four experimental groups with litter weight at birth (Lw 0$)$ and on days of lactation (Lw $1,2,7,14$ and 21)

\begin{tabular}{|c|c|c|c|c|c|c|}
\hline & Lw 0 & Lw 1 & Lw 2 & Lw 7 & Lw 14 & Lw 21 \\
\hline Insulin D-1 & $-0.420^{\star \star}$ & $-0.441^{\star *}$ & $-0.412^{\star \star}$ & $-0.304^{*}$ & $-0.280^{\star}$ & -0.263 \\
\hline Leptin D-4 & -0.196 & -0.201 & -0.221 & $-0.355^{\star *}$ & $-0.336^{\star *}$ & $-0.302^{*}$ \\
\hline
\end{tabular}

${ }^{\star} P<0.05,{ }^{\star \star} P<0.01$.

on leptin, the time point of transition from a gestation to a lactation diet profoundly influenced piglet weight at birth and at subsequent stages. Any separate effect of $n-6$ and $n-3$ PUFA and pre-partum feeding strategy on insulin, thyroid hormones, leptin, rectal temperature, feed intake of sows in the periparturient period and the piglet growth in the early days of lactation should not be disregarded, but these effects should be considered as a whole. This approach should be a prerequisite to a better understanding of the pathogenesis of postpartum dysgalactia syndrome from a clinical nutrition approach. According to the present results, a diet low in the $n-6: n-3$ ratio (fish oil-supplemented diet) provided $8 \mathrm{~d}$ before the expected farrowing was the most appropriate combination.

Table 7. Associations (Pearson's correlation; $r$ ) between sow leptin levels from all experimental groups on the fourth and third day before farrowing (D-4 and D-3 respectively) with litter growth (Lgr) between different stages of lactation

\begin{tabular}{llllll}
\hline & Lgr 1-2 & Lgr 0-2 & Lgr 0-7 & Lgr 7-14 & Lgr 14-21 \\
\hline Leptin D-4 & -0.197 & -0.165 & $-0.395^{\star \star}$ & $-0.278^{\star}$ & -0.192 \\
Leptin D-3 & $-0.335^{\star \star}$ & $-0.362^{\star \star}$ & $-0.405^{\star \star}$ & $-0.255^{\star}$ & $-0.262^{\star}$ \\
\hline
\end{tabular}

${ }^{\star} P<0.05,{ }^{* \star} P<0.01$ 


\section{Acknowledgements}

Expenses for the laboratory analyses were covered by the scholarship programme awarded to G. A. P. by the Greek State Scholarship Foundation for postgraduate study abroad (www.iky.gr). G. A. P. was responsible for the study design, study performance, parameter analysis, data analysis and manuscript drafting. T. A. T. G. V. K. was responsible for the supervision of logistic arrangements, experimental diet development, and had a contribution in manuscript drafting. J. B. supervised the analysis of blood parameters and had a contribution in the manuscript drafting. S. V. W. participated in the study performance and in manuscript drafting. D. G. D. M. and G. P. J. J. evaluated the study design, also contributed to data analysis and manuscript drafting, and both are promoters of G. A. P. It is declared by the corresponding author that no conflict of interest exists for this manuscript.

\section{References}

1. Rooke JA, Sinclair AG \& Edwards SA (2001) Feeding tuna oil to the sow at different times during pregnancy has different effects on piglet long-chain polyunsaturated fatty acid composition at birth and subsequent growth. Br J Nutr 86, 21-30.

2. Wiseman $\mathbf{J}$ (2006) Value of fats and oils in pig diets. In Whittemore's Science and Practice of Pig Production, 3rd ed., pp. 368-378 [I Kyriazakis and CT Whittemore, editors]. Oxford: Blackwell Publishing.

3. Calder PC \& Grimble RF (2002) Polyunsaturated fatty acids, inflammation and immunity. Eur J Clin Nutr 56, Suppl. 3, S14-S19.

4. Calder PC (2006) n-3 Polyunsaturated fatty acids, inflammation, and inflammatory diseases. Am J Clin Nutr 83, Suppl. 6, 1505S-1519S

5. Storlien LH, Kriketos AD, Calvert GD, Baur LA \& Jenkins AB (1997) Fatty acids, triglycerides and syndromes of insulin resistance. Prostaglandins Leukot Essent Fatty Acids 57, 379-385.

6. Storlien LH, Kraegen EW, Chisholm DJ, Ford GL, Bruce DG \& Pascoe WS (1987) Fish oil prevents insulin resistance induced by high-fat feeding in rats. Science 237, 885-888.

7. Storlien LH, Jenkins AB, Chisholm DJ, Pascoe WS, Khouri S \& Kraegen EW (1991) Influence of dietary fat composition on development of insulin resistance in rats, relationship to muscle triglyceride and $\omega-3$ fatty acids in muscle phospholipid. Diabetes 40, 280-289.

8. Weldon WC, Lewis AJ, Louis GF, Kovar JL \& Miller PS (1994) Postpartum hypophagia in primiparous sows: II. Effects of feeding level during gestation and exogenous insulin on lactation feed intake, glucose tolerance, and epinephrine-stimulated release of nonesterified fatty acids and glucose. J Anim Sci 72, 395-403

9. Rooke JA, Sinclair AG, Edwards SA, Cordoba R, Pkiyach S, Penny PC, Finch AM \& Horgan GW (2001) The effect of feeding salmon oil to sows throughout pregnancy on pre-weaning mortality of piglets. Anim Sci 73, 489-500.

10. Rooke JA, Shanks M \& Edwards SA (2000) Effect of offering maize, linseed or tuna oils throughout pregnancy and lactation on sow and piglet tissue composition and piglet performance. Anim Sci 71, 289-299.

11. Rooke JA, Bland IM \& Edwards SA (1998) Effect of feeding tuna oil or soyabean oil as supplements to sows in late pregnancy on piglet tissue composition and viability. $B r J$ Nutr 80, 273-280.
12. Nachreiner RF \& Ginther OJ (1972) Gestational and periparturient periods of sows: serum chemical, hematologic, and clinical changes during the periparturient period. Am J Vet Res 33, $2233-2238$.

13. Neil M (1996) Ad libitum lactation feeding of sows introduced immediately before or after farrowing. Anim Sci 63, 497-505.

14. Klopfenstein C, Farmer C \& Martineau GP (2006) Diseases of the mammary glands. In Diseases of Swine, 9th ed., pp. 57-74 [BE Straw, JJ Zimmerman, S D'Allaire and DJ Taylor, editors]. Oxford: Blackwell Publishing.

15. Neil M, Ogle B \& Anner K (1996) A two-diet system and ad libitum lactation feeding of the sow 1 . Sow performance. Anim Sci 62, 337-347.

16. Göransson L (1989) The effect of feed allowance in late pregnancy on the occurrence of agalactia post partum in the sow. J Vet Med A 36, 505-513.

17. Bontempo V, Sciannimanico D, Pastorelli G, Rossi R, Rosi F \& Corino C (2004) Dietary conjugated linoleic acid positively affects immunologic variables in lactating sows and piglets. J Nutr 134, 817-824.

18. Fritsche KL, Huang SC \& Cassity NA (1993) Enrichment of omega-3 fatty acids in suckling pigs by maternal dietary fish oil supplementation. J Anim Sci 71, 1841-1847.

19. Lauridsen C \& Danielsen V (2004) Lactational dietary fat levels and sources influence milk composition and performance of sows and their progeny. Liv Prod Sci 91, 95-105.

20. Govoni N, Parmeggiani A, Galeati G, Penazzi P, De Iasio R, Pagotto U, Pasquali R, Tamanini C \& Seren E (2007) Acyl ghrelin and metabolic hormones in pregnant and lactating sows. Reprod Domest Anim 42, 39-43.

21. Eder K, Ramanau A, Kluge H \& Spilke J (2004) Supplementation of sows with L-carnitine during pregnancy and lactation improves growth of the piglets during the suckling period through increased milk production. J Nutr 134, 86-92.

22. Eder K, Ramanau A, Kluge H \& Spilke J (2008) Effects of dietary supplementation of L-carnitine on the reproductive performance of sows in production stocks. Livestock Sci 113, 34-42.

23. Barb CR, Hausmana GJ \& Houseknecht KL (2001) Biology of leptin in the pig. Domest Anim Endocrinol 21, 297-317.

24. Whisnant CS \& Harrell RJ (2002) Effect of short-term feed restriction and refeeding on serum concentrations of leptin, luteinizing hormone and insulin in ovariectomized gilts. Domest Anim Endocrinol 22, 73-80.

25. Kemp B, Soede NM, Vesseur PC, Helmond FA, Spoorenberg JH \& Frankena K (1996) Glucose tolerance of pregnant sows is related to postnatal pig mortality. J Anim Sci 74, 879-885.

26. McPherson RL, Ji F, Wu G, Blanton JR \& Kim SW (2004) Growth and compositional changes of fetal tissues in pigs. J Anim Sci 82, 2534-2540.

27. Barb CR, Yan X, Azain MJ, Kraeling RR, Rampacek GB \& Ramsay TG (1998) Recombinant porcine leptin reduces feed intake and stimulates growth hormone secretion in swine. Domest Anim Endocrinol 15, 77-86.

28. Niswender KD, Baskin DG \& Schwartz MW (2004) Insulin and its evolving partnership with leptin in the hypothalamic control of energy homeostasis. Trends Endocrinol Metab 15, 362-369.

29. Bauman DE \& Currie WB (1980) Partitioning of nutrients during pregnancy and lactation: a review of mechanisms involving homeostasis and homeorhesis. J Dairy Sci 63, $1514-1529$.

30. Behme MT (1996) Dietary fish oil enhances insulin sensitivity in miniature pigs. $J$ Nutr 126, 1549-1553.

31. Herman MA \& Kahn BB (2006) Glucose transport and sensing in the maintenance of glucose homeostasis and metabolic harmony. J Clin Invest 116, 1767-1775. 
32. Rojkittikhun T, Einarsson S, Uvnäs-Moberg K \& Edqvist LE (1993) Body weight loss during lactation in relation to energy and protein metabolism in standard-fed primiparous sows. $J$ Vet Med A 40, 249-257.

33. Tucker HA (1985) Endocrine and neural control of the mammary gland. In Lactation, pp. 39-79 [BL Larson, editor]. Ames, IA: The Iowa State University Press.

34. Wagner WC (1972) Endocrine function in normal and agalactic sows. J Anim Sci 34, 270-272.

35. Woodside B, Abizaid A \& Walker CD (2000) Changes in leptin levels during lactation: implications for lactational hyperphagia and anovulation. Horm Behav 37, 353-365.
36. Ashworth C (2006) Reproduction. In Whittemore's Science and Practice of Pig Production, 3rd ed., pp. 104-147 [I Kyriazakis and CT Whittemore, editors]. Oxford: Blackwell Publishing.

37. Doberenz J, Birkenfeld C, Kluge H \& Eder K (2006) Effects of L-carnitine supplementation in pregnant sows on plasma concentrations of insulin-like growth factors, various hormones and metabolites and chorion characteristics. J Anim Physiol Anim Nutr (Berl) 90, 487-499.

38. Zhu Y, Österlundh I, Hultén F \& Magnusson U (2004) Tumor necrosis factor- $\alpha$, interleukin-6, serum amyloid A, haptoglobin, and cortisol concentrations in sows following intramammary inoculation of Escherichia coli. Am J Vet Res 65, 1434-1439. 